\title{
GC-MS Analysis of Phyto-Constituents of the Essential Oil from the Leaves of Melaleuca citrina (Curtis) Dum.Cours.
}

\author{
Manikandan G.*, Saranya M., Gayathri S. \\ Department of Botany, Sri Kaliswari College (Autonomous), Sivakasi, Virudhunagar, Tamil Nadu, India
}

Received December 30, 2019; Revised February 21, 2020; Accepted February 24, 2020

Copyright $\bigcirc 2020$ by authors, all rights reserved. Authors agree that this article remains permanently open access under the terms of the Creative Commons Attribution License 4.0 International License

\begin{abstract}
Melaleuca citrina (Curtis) Dum. Cours. commonly known as 'red bottle brush', is one of those medicinal plants with great medicinal importance. It is a beautiful evergreen tree belonging to the family Myrtaceae. It is indigenous to Queensland and New South Wales and cultivated throughout India in gardens. The plant is known in folk medicine for its anticough, antibronchitis, insecticidal effects and its volatile oil has been used as antimicrobial and antifungal agents. Moreover, aerial parts of Melaleuca citrina are practiced traditionally in ethnic tribal communities and very little are known about its importance on scientific grounds. The present study conducted to explore the Phyto-Constituents of the essential oil from the leaves of Melaleuca citrina. In the present analysis, the phyto-constituents of the leaves of essential oil of Melaleuca citrina by GC-MS analysis clearly showed the presence of 19 compounds. The results revealed that Eucalyptol (55.14\%), Octadien-3-ol, 3,7dimethyl- (11.48\%), 1,5-Dimethyl-1-vinyl-4-hexenyl butyrate (11.48\%), L-.alpha.-Terpineol (16.25\%) and .alpha.-Terpineol (16.25\%) were reported as 5 major components in the essential oil leaves of the Melaleuca citrina. Eucalyptol is an ingredient in many brands of mouthwash and cough suppressant. Eucalyptol is an effective treatment for nonpurulent rhinosinusitis. Eucalyptol reduces inflammation and pain when applied topically. It kills leukaemia cells. The essential oils from leaves of Melaleuca citrina may serve as potent natural anti-cancer compounds with important roles in human health.
\end{abstract}

Keywords Phyto-Constituents, Leaves, Essential oil, Eucalyptol, Leukaemia

\section{Introduction}

Plants have been an important source of medicine for thousands of years. Use of plants for the treatment of many diseases dated back to prehistory and people of all continents have this old tradition. Every culture on earth has relied on the vast variety of natural chemistries' found in plants for their therapeutic properties. Plants are known to produce a variety of compounds to protect themselves against a variety of pathogens. Medicinal plants represent a rich source of antimicrobial agents. Plants are used medicinally in different countries and are a source of many potent and powerful drugs. The medicinal value of plants lies in some chemical substances that produce a definite physiological action on the human body [1].

Plants used for traditional medicine contain a wide range of substances that can be used to treat chronic as well as infectious diseases. A vast knowledge of how to use the plants against different illnesses may be expected to have accumulated in areas where the use of plants is still of great importance [2]. Plant synthesizes a wide variety of chemical compounds, which can be sorted by their chemical class, biosynthetic origin and functional groups into primary and secondary metabolites. Primary metabolites make up the physical integrity of the plant cell and are involved with the primary metabolite process of building and maintaining of living cells [3].

Melaleuca citrina (Curtis) Dum. Cours. commonly known as 'red bottle brush', is one of those medicinal plants with great medicinal importance. The name of the plant, Callistemon, is derived from Greek kalos meaning beautiful and stemon meaning stamens and citrinus from Latin citrinus meaning lemon, referring to the scent of the leaves. It is a beautiful evergreen tree belonging to the family Myrtaceae. It is indigenous to Queensland and New South Wales and cultivated throughout India in gardens. 
The plant is commonly named as bottle brush because the cylindrical brush like flowers resembles traditional bottle brush. Different parts of the plant are used by rural people of India. The plant is known in folk medicine for its anticough, antibronchitis, insecticidal effects and its volatile oil has been used as antimicrobial and antifungal agents. Moreover, aerial parts of Melaleuca citrina are practiced traditionally in ethnic tribal communities and very little are known about its importance on scientific grounds.

The leaves of Melaleuca citrina were evergreen, aromatic, alternate, lanceolate with entire margin and anomocytic stomata. Stem was grey in colour. Phytochemical study on leaves reported the presence of flavonoids, alkaloids, terpenoids and steroids. As there is no detailed record of research work available on GC-MS analysis of Phyto-Constituents of the essential oil from the leaves of M.citrina. This is the first report on the chemical composition of essential oil of leaves from this species. The aim of the present study is to analyse the bioactive compounds of the essential oil from the leaves of Melaleuca citrina.

\section{Materials and Methods}

\subsection{Collection of Plant Materials}

The fresh leaves of Melaleuca citrina were collected from the campus of Sri Kaliswari College (Autonomous), Sivakasi. The collected specimens were properly identified with the standard literature and authenticated with valid voucher specimens. The voucher specimens were deposited in the herbarium of Department of Botany, SKC.

\subsection{Extraction of Essential Oil through Hydro- Distillation Method}

The chopped fresh leaves of Melaleuca citrina were subjected into Clevenger type apparatus by using hydrodistillation for about 2-3 hrs. The essential oils were extracted then, the oils were collected separately and dehydrated over anhydrous sodium sulfate and stored in air tight vials at $4^{\circ} \mathrm{C}$ for further study.

\subsection{Phytochemical Analysis by GC-MS}

GC-MS analysis of extracted essential oils were performed by using a Shimadzu GC-MS QP2010 Ultra model and Gas Chromatograph interfaced to a mass spectrometer (GC-MS) equipped with a Rxi-5Sil MS, fused silica capillary column $(30 \mathrm{ml} \times 0.25 \mathrm{~mm} \mathrm{ID} \times 1 \times \mathrm{df}$, composed of $100 \%$ Dimethyl polysiloxane1,4bis(dimethylsiloxy) phenylene dimethyl polysiloxane). For GC/MS detection, an electron ionization system with an ionizing energy of $70 \mathrm{eV}$ was used. Helium gas $(99.999 \%)$ was used as the carrier gas at constant flow rate $1 \mathrm{ml} / \mathrm{min}$ and an injection volume of $1 \mu 1$ was employed (Split ratio of 50:1) injector temperature $250^{\circ} \mathrm{C}$; ionsource temperature $280^{\circ} \mathrm{C}$. The oven temperature was programmed from $100^{\circ} \mathrm{C}$ (isothermal for $2 \mathrm{~min}$ ) with an increase of $5^{\circ} \mathrm{C} / \mathrm{min}$ to $200^{\circ} \mathrm{C}$, then $10^{\circ} \mathrm{C} / \mathrm{min}$ to $280^{\circ} \mathrm{C}$, ending with a $2 \mathrm{~min}$ isothermal at $280^{\circ} \mathrm{C}$. Mass spectra were taken at $70 \mathrm{eV}$; a scan interval of 0.3 seconds and fragments from 40 to 800 Da total GC running time was 32 minutes and the software adopted to handle mass spectra and chromatograms was a Lab Solutions.

\subsection{Identification of Phytochemical Components}

The identity of the components in the extracts was assigned by the comparison of their retention indices and mass spectra fragmentation patterns with those stored on the computer library and also with published literatures. NIST08s.LIB, WILEY8. LIB library sources were used for matching the identified components from the essential oil.

\section{Results and Discussion}

Medicinal plant possesses many bioactive compounds including phenolic and polyphenolic compounds which play key function in detoxification of stress induced by free radicles and exhibit antimicrobial activities [4]. Plants act as important source for all treatments in traditional medical system of the world. The Herbal plants have been used for medical treatment since ancient times [5]. The plants are traditionally used to treat thorn or glass-puncture wounds, abscesses [6], Scrofulosis, carbuncles, dysentery, Rheumatism, isthmus and crural aches, fractures, superficial infections, fingernail inflammation, tumor, difficult labour and pueral pain [7].

The GC-MS analysis of Phyto-Constituents of the essential oil from the leaves of Melaleuca citrina is shown in the table 1. The GC-MS identification of the phytoconstituents was based on comparison of their mass spectra with NIST and WILEY libraries. Structures were defined by percentage similarity values. The identification of the chemical compounds was confirmed based on the peak area, retention time and mass spectrum. In this present analysis, the phyto-constituents of the leaves of essential oil of Melaleuca citrina by GC-MS analysis clearly showed the presence of 19 compounds. In GC-MS analysis, Melaleuca citrina showed 5 major and 14 minor compounds (Figure 1.). 


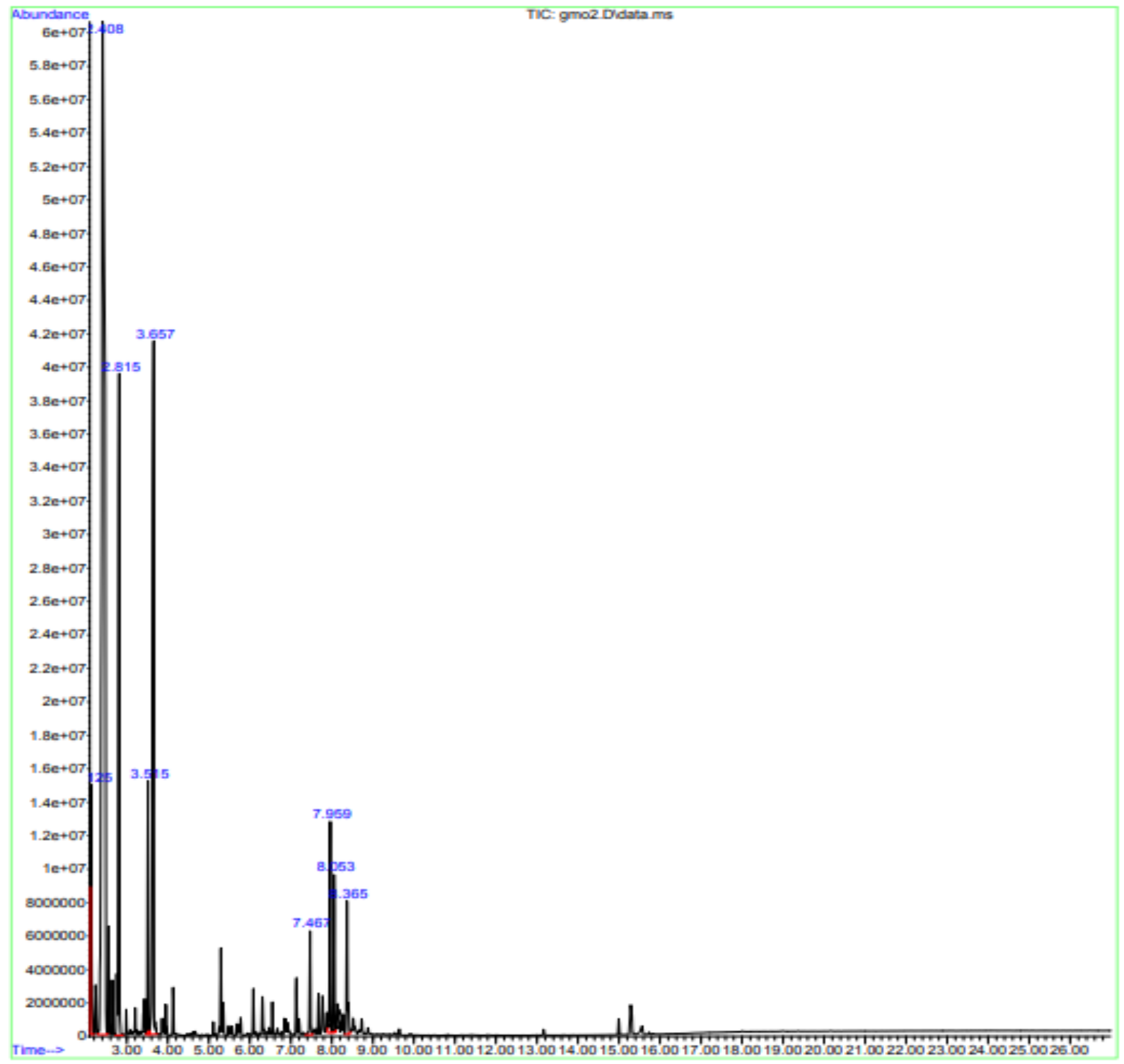

Figure 1. GC-MS Chromatogram of Phyto-Constituents identified from essential oil of Melaleuca citrina 
Table 1. List of Phyto-Constituents identified from essential oil of Melaleuca citrina through GC-MS analysis

\begin{tabular}{|c|c|c|c|c|}
\hline S.No. & RT & Name of the Compounds & Area $\%$ & Mass Spectrum \\
\hline 1. & 2.125 & beta.-Pinene & 3.30 & 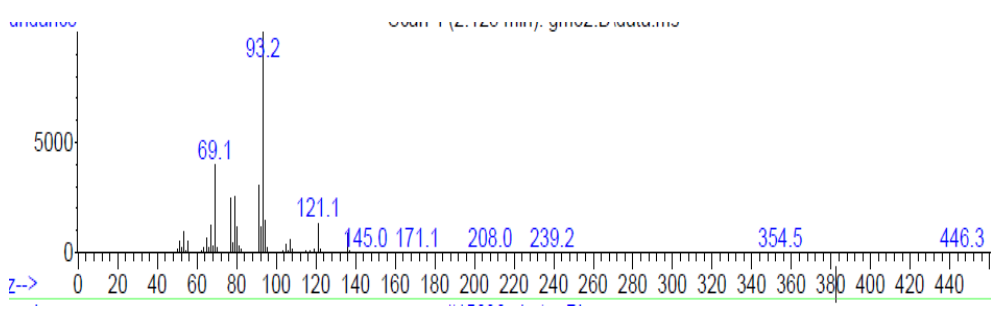 \\
\hline 2. & 2.125 & Bicyclo[3.1.1] heptane, 6,6-dimethyl-2-methylene-, (1S)- & 3.30 & m/z-> \\
\hline 3. & 2.408 & Eucalyptol & 55.14 & 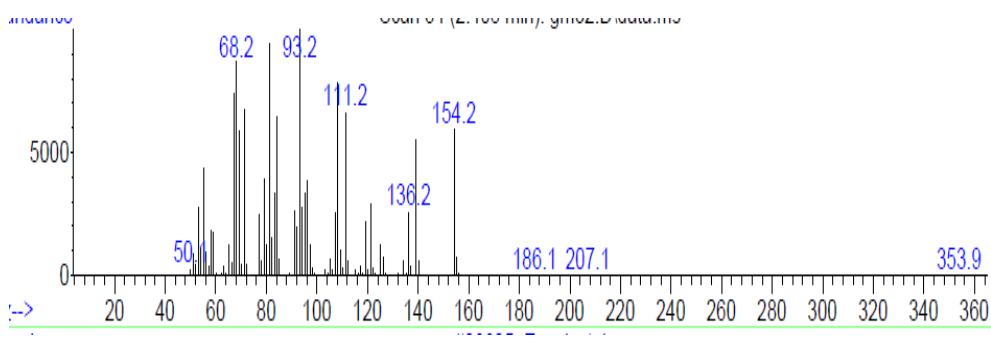 \\
\hline 4. & 2.815 & Octadien-3-ol, 3,7-dimethyl- & 11.48 & 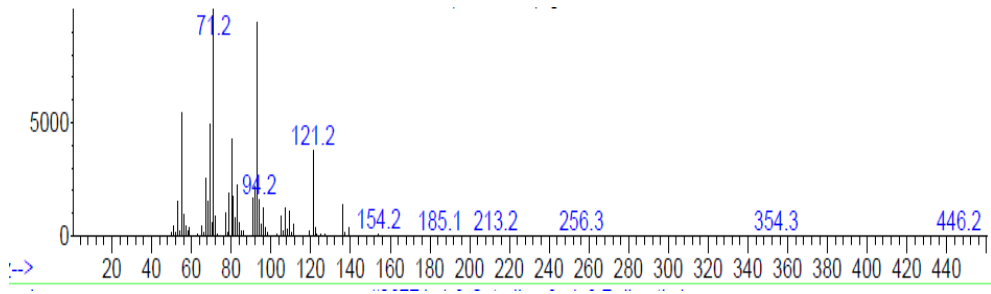 \\
\hline
\end{tabular}


Table 1 Continued

\begin{tabular}{|c|c|c|c|c|}
\hline 5. & 2.815 & 1,5-Dimethyl-1-vinyl-4-hexenyl butyrate & 11.48 & 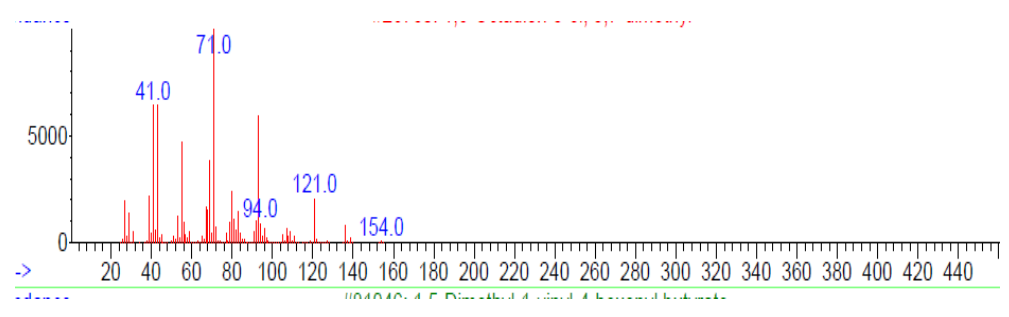 \\
\hline 6. & 3.515 & Terpinen-4-ol & 3.39 & 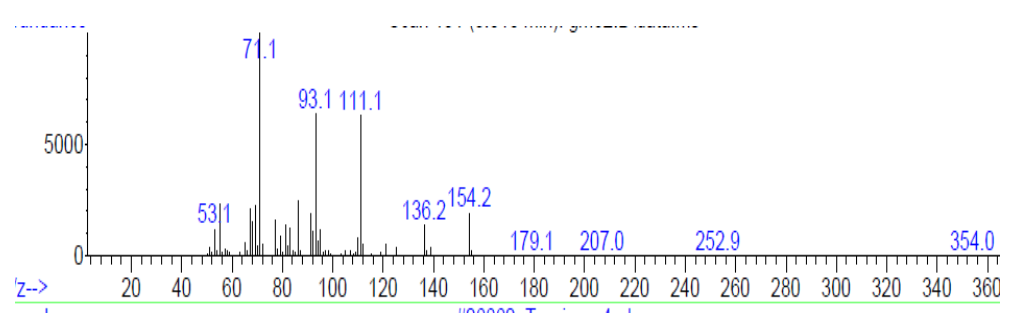 \\
\hline 7. & 3.515 & 3-Cyclohexen-1-ol, 4-methyl-1-(1-methylethyl)-, (R)- & 3.39 & 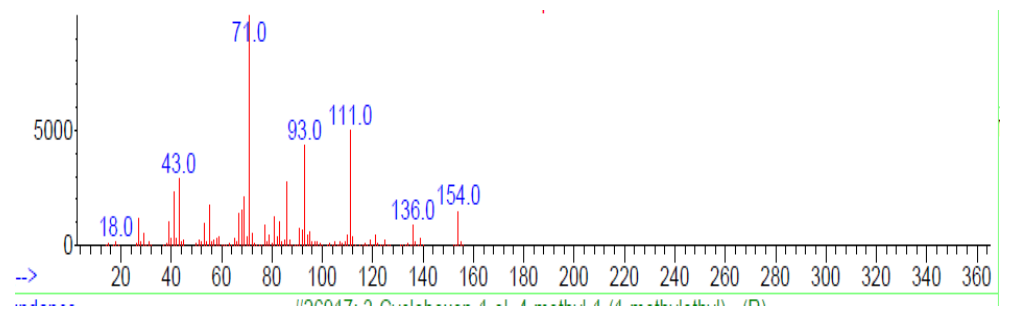 \\
\hline 8. & 3.657 & L-.alpha.-Terpineol & 16.25 & 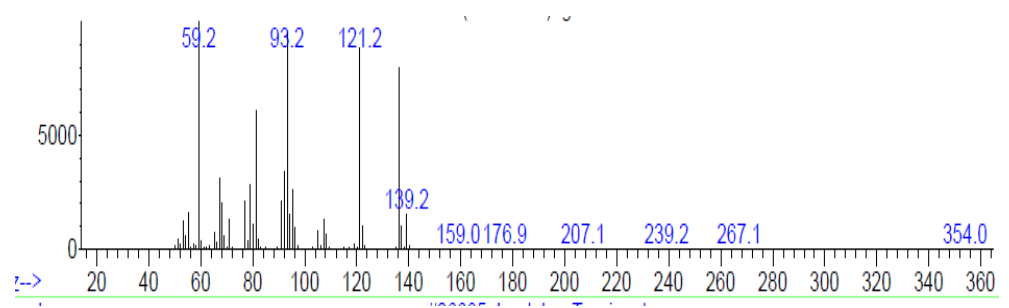 \\
\hline
\end{tabular}


Table 1 Continued

\begin{tabular}{|c|c|c|c|c|}
\hline 9. & 3.657 & alpha.-Terpineol & 16.25 & 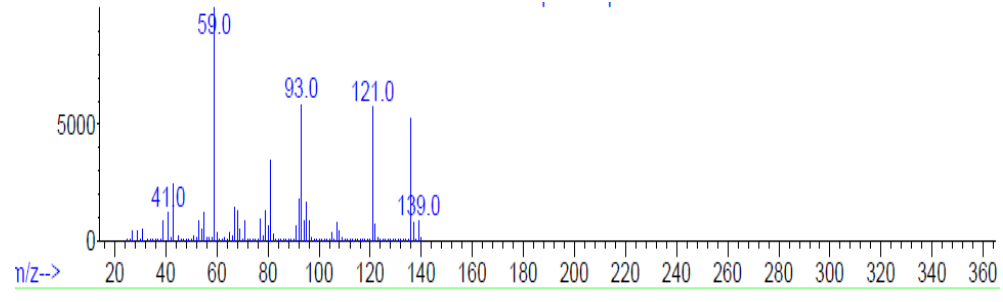 \\
\hline 10. & 7.467 & Benzene, 1,2,3-trimethoxy-5-(2-propenyl)- & 1.66 & 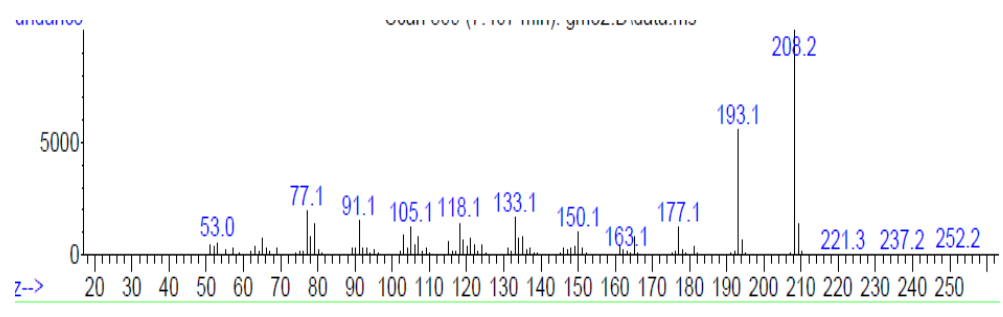 \\
\hline 11. & 7.959 & (-)-Globulol & 3.56 & 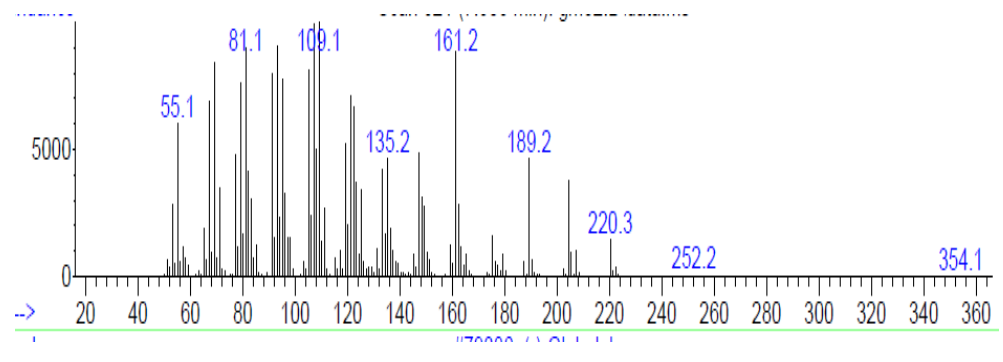 \\
\hline 12 & 7.959 & $\begin{array}{l}\text { Naphthalene, decahydro-4a-methyl-1-methylene-7-(1-methylethylidene)-, } \\
\text { (4aR-trans)- }\end{array}$ & 3.56 & $\underbrace{}_{z->}$ \\
\hline
\end{tabular}


Table 1 Continued

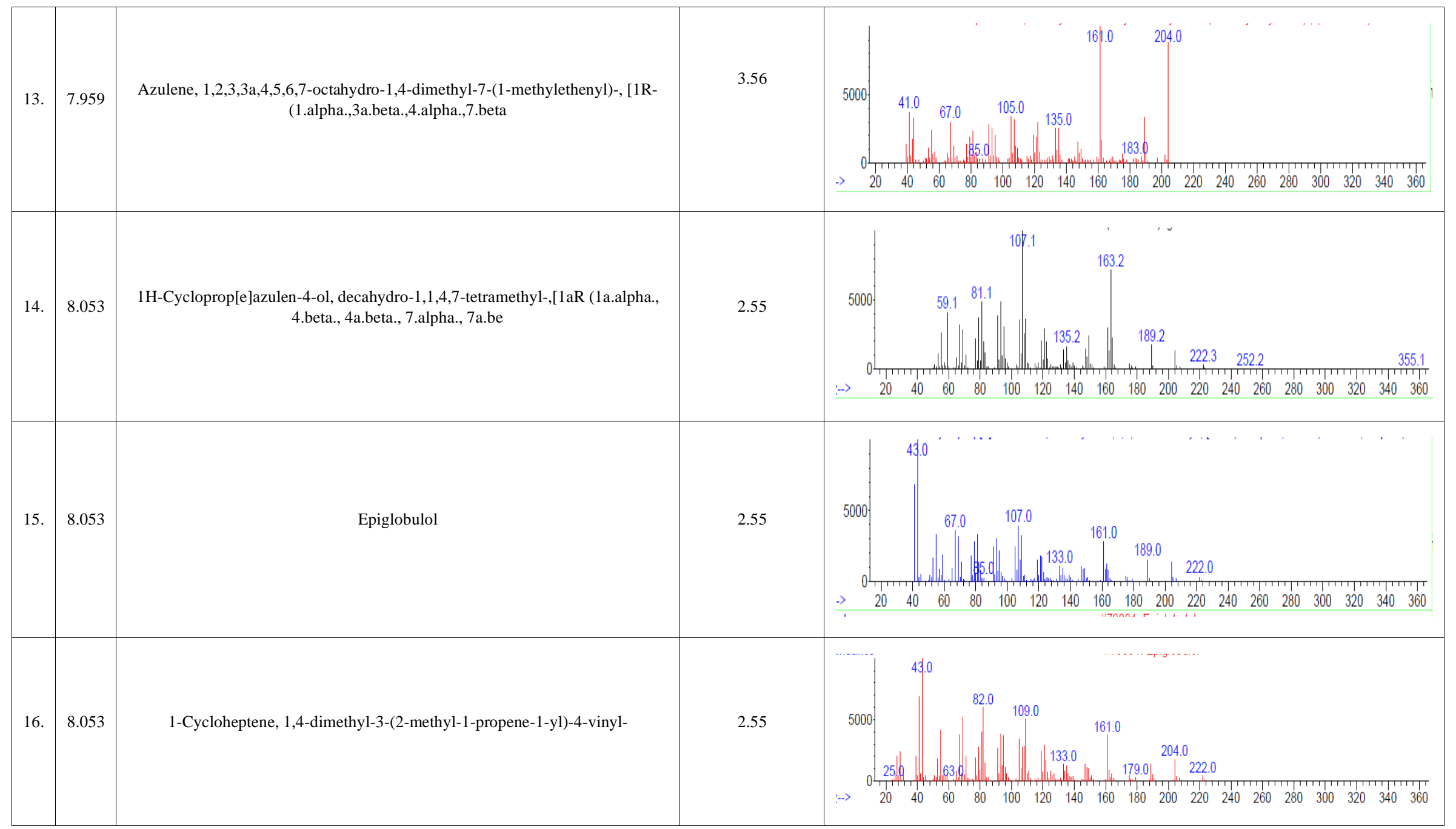


Table 1 Continued

\begin{tabular}{|c|c|c|c|c|}
\hline 17. & 8.365 & 1H-Indene, 1-ethylideneoctahydro-7a-methyl-, (1Z,3a.alpha.,7a.beta.)- & 2.66 & 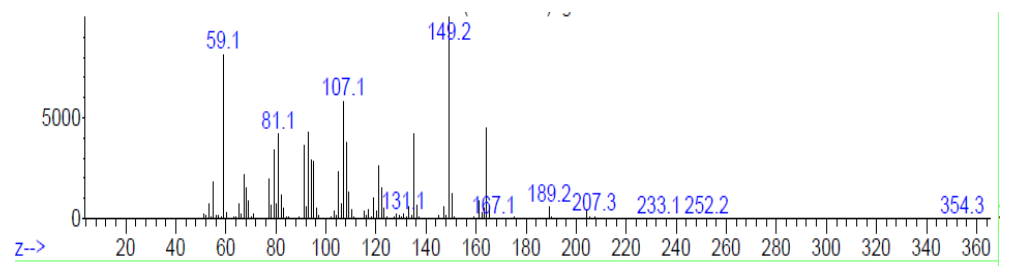 \\
\hline 18. & 8.365 & $\begin{array}{l}\text { 2-Naphthalenemethanol, decahydro-.alpha.,.alpha.,4a-trimethyl-8-methylene-, } \\
\text { [2R-(2.alpha.,4a.alpha.,8a.be }\end{array}$ & 2.66 & $\begin{array}{l}5000 \\
2 \rightarrow .>\end{array}$ \\
\hline 19. & 8.365 & $\begin{array}{c}\text { 2-Naphthalenemethanol, 2,3,4,4a,5,6,7,8-octahydro-.alpha.,.alpha.,4a,8- } \\
\text { tetramethyl-, [2R-(2.alpha.,4a.beta. }\end{array}$ & 2.66 & 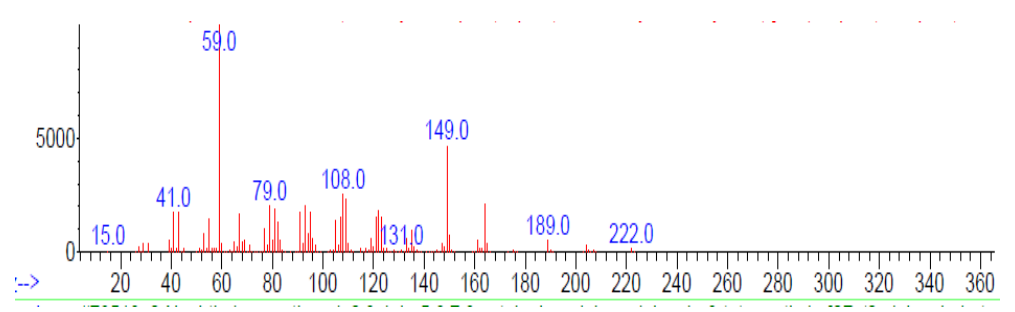 \\
\hline
\end{tabular}

RT-Retention Time 
The results revealed that Eucalyptol (55.14\%), Octadien3-ol, 3,7-dimethyl- (11.48\%), 1,5-Dimethyl-1-vinyl-4hexenyl butyrate (11.48\%), L-.alpha.-Terpineol (16.25\%) and .alpha.-Terpineol $(16.25 \%)$ were reported as 5 major components in the essential oil leaves of the Melaleuca citrina. The 14 minor compounds such as .beta.-Pinene (3.30\%), Bicyclo[3.1.1]heptane, 6,6-dimethyl-2methylene-, (1S)- (3.30\%), Terpinen-4-ol (3.39\%), 3Cyclohexen-1-ol, 4-methyl-1-(1-methylethyl)-, (R)(3.39\%), Benzene, 1,2,3-trimethoxy-5-(2-propenyl)(1.66\%), (-)-Globulol (3.56\%), Naphthalene, decahydro4a-methyl-1-methylene-7-(1-methylethylidene)-, (4aRtrans)- (3.56\%), Azulene, 1,2,3,3a,4,5,6,7-octahydro-1,4dimethyl-7-(1-methylethenyl)-, [1R-(1.alpha., 3a.beta., 4.alpha., 7.beta (3.56\%), 1H-Cycloprop[e]azulen-4-ol, decahydro-1,1,4,7-tetramethyl-,[1aR (1a.alpha., 4.beta., 4a.beta., 7.alpha., 7a.be (2.55\%), Epiglobulol (2.55\%), 1Cycloheptene, 1,4-dimethyl-3-(2-methyl-1-propene-1-yl)4-vinyl- (2.55\%), 1H-Indene, 1-ethylideneoctahydro-7amethyl-, (1Z,3a.alpha.,7a.beta.)- (2.66\%), 2Naphthalenemethanol, decahydro-.alpha.,.alpha.,4atrimethyl-8-methylene-, [2R-(2.alpha.,4a.alpha.,8a.be (2.66\%) and 2-Naphthalenemethanol, 2,3,4,4a,5,6,7,8octahydro-.alpha.,.alpha.,4a,8-tetramethyl-,

$[2 \mathrm{R}-$ (2.alpha.,4a.beta. (2.66\%).

[8]Previously Dharmesh Kumar et al., 2015 reported that, the GC and GC-MS analysis of Callistemon citrinus essential oils revealed high content of $\alpha$-pinene $(32.3 \%)$, limonene (13.1\%) and $\alpha$-terpineol (14.6\%) in leaf sample, whereas the flower oil was dominated by 1,8-cineole (36.6\%) followed by $\alpha$-pinene $(29.7 \%)$. The leaf oil contained higher amount of monoterpene hydrocarbons $(52.1 \%)$ and sesquiterpenoids (14\%) as compared to flower oil ( $44.6 \%$ and $1.2 \%$, respectively). However, the flower oil was predominant in oxygenated monoterpenes $(43.5 \%)$.

[9]Manohar et al., 2014 reported that, the chemical composition of the essential oil of Inula viscosa (L.) leaves, obtained by both hydrodistillation and steam distillation, was investigated by GC-MS. The major components for hydrodistillation was 12-carboxyeudesma-3,11(13)-diene (28.88\%); linolenic acid (7.80\%); palmitic acid (5.38\%); butyl hydroxy toluene (4.11\%) and fokienol (3.37\%), while for steam distillation were: 12-carboxyeudesma-3,11 (13)diene $(56.81 \%)$; 2,3-didehydrocostic acid (3.25\%); butyl hydroxy toluene $(2.63 \%)$ and pentacosane $(2.31 \%)$.Seed oil of Garcinia xanthochymus composed of nine major fatty acids including myristic acid $(0.11 \%)$, palmitic acid (32.96\%), oleic acid (45.87\%), stearic acid (0.96\%), palmitoleic acid $(17.65 \%)$, linoleic acid $(1.93 \%)$, linolenic acid $(0.34 \%)$, arachidic acid $(0.07 \%)$ and behenic acid $(0.07 \%)$. The oil also demonstrated for antimicrobial activity against gram positive bacteria [10].

[3] Manikandan et al., 2017 reported that the leaves of Petroleum ether extract of Millettia peguensis by GC-MS analysis clearly showed the presence of 10 compounds. The results revealed that Pentadecane $(32.73 \%)$, Tetradecane $(29.79 \%)$ and Octadecane $(22.77 \%)$ was reported as 3 major components in the Petroleum ether leaves extract of the Millettia peguensis. The seven minor compounds such as Eicosane (7.23\%), Undecane, 5-methyl- (2.13\%), 9methylheptadecane (1.40\%), Sulfurous acid, dodecyl hexyl ester (1.13\%), Heptadecane, 2,6,10,15-tetramethyl$(0.99 \%)$, 2-Bromo dodecane $(0.96 \%)$ and Heneicosane $(0.87 \%)$ was also reported from leaves.

In this present study, High amount $(55.14 \%)$ of Eucalyptol compound present in leaf essential oil in the Melaleuca citrina. Eucalyptol, 1,8 cineole, is an essential oil present in large amounts in a variety of plants which is frequently used in the manufacture of cosmetics, to increase percutaneous penetration of drugs, as a nasal decongestant and anticough agent, in aromatherapy, and in dentistry [11-14]. Eucalyptol is naturally produced cyclic ether and monoterpenoid. Eucalyptol is an ingredient in many brands of mouthwash and cough suppressant. It controls airway mucus hyper secretion and asthma via antiinflammatory cytokine inhibition. Eucalyptol is an effective treatment for nonpurulent rhinosinusitis. Eucalyptol reduces inflammation and pain when applied topically. It kills leukaemia cells in vitro. The uses of identified phyto-constituents of leaf essential oil of the Melaleuca citrina are shown in table 2. 
Table 2. Uses of Phyto-Constituents identified from essential oil of Melaleuca citrina

\begin{tabular}{|c|c|c|}
\hline S.No. & Name of the Compounds & Uses \\
\hline 1. & .beta.-Pinene & Anti-depressant, Antibacterial \& Antimicrobial activity. \\
\hline 2. & $\begin{array}{l}\text { Bicyclo[3.1.1]heptane, 6,6-dimethyl-2-methylene-, } \\
\text { (1S)- }\end{array}$ & Odor agents \\
\hline 3. & Eucalyptol & Cosmetics, Treatment of Alopecia with Monoterpenoids \\
\hline 4. & Octadien-3-ol, 3,7-dimethyl- & Flavoring agents \\
\hline 5. & 1,5-Dimethyl-1-vinyl-4-hexenyl butyrate & Anti-parasitic, Anti-bacterial \& Antimicrobial activities. \\
\hline 6. & Terpinen-4-ol & Antimicrobial and antioxidant activities. \\
\hline 7. & 3-Cyclohexen-1-ol, 4-methyl-1-(1-methylethyl)-, (R)- & Cough suppressant, Anti-Infective Agents \&Protective Agents \\
\hline 8. & L-.alpha.-Terpineol & Disinfectants, antioxidants medicines and constituent of flavourings. \\
\hline 9. & alpha.-Terpineol & Antiulcer, anticancer \& antibronchitis activity. \\
\hline 10. & Benzene, 1,2,3-trimethoxy-5-(2-propenyl)- & Antioxidant effects, anti-inflammatory and antithrombotic effect. \\
\hline 11. & (-)-Globulol & Antimicrobial and Anti-inflammatory. \\
\hline 12. & $\begin{array}{l}\text { Naphthalene, decahydro-4a-methyl-1-methylene-7-(1- } \\
\text { methylethylidene)-, (4aR-trans)- }\end{array}$ & Antimicrobial, Antioxidant and medicine of skin disease. \\
\hline 13. & $\begin{array}{l}\text { Azulene, 1,2,3,3a,4,5,6,7-octahydro-1,4-dimethyl-7-(1- } \\
\text { methylethenyl)-, [1R-(1.alpha.,3a.beta.,4.alpha.,7.beta }\end{array}$ & Anti-inflammatory and Anti-cancer. \\
\hline 14. & $\begin{array}{l}\text { 1H-Cycloprop[e]azulen-4-ol, decahydro-1,1,4,7- } \\
\text { tetramethyl-,[1aR (1a.alpha., 4.beta., 4a.beta., 7.alpha., } \\
\text { 7a.be }\end{array}$ & Anti-proliferative activity and Antimicrobial activity. \\
\hline 15. & Epiglobulol & Anti-perspirants or body deodorants. \\
\hline 16. & $\begin{array}{l}\text { 1-Cycloheptene, 1,4-dimethyl-3-(2-methyl-1-propene- } \\
\text { 1-yl)-4-vinyl- }\end{array}$ & Colourings, flavours, etc added to food for human consumption. \\
\hline 17. & $\begin{array}{l}\text { 1H-Indene, 1-ethylideneoctahydro-7a-methyl-, } \\
\text { (1Z,3a.alpha.,7a.beta.)- }\end{array}$ & Antimicrobial and Antioxidant. \\
\hline 18. & $\begin{array}{l}\text { 2-Naphthalenemethanol, decahydro-.alpha.,.alpha.,4a- } \\
\text { trimethyl-8-methylene-, [2R-(2.alpha.,4a.alpha.,8a.be }\end{array}$ & Anti-inflammatory and medicine of skin disease. \\
\hline 19. & $\begin{array}{l}\text { 2-Naphthalenemethanol, 2,3,4,4a,5,6,7,8- } \\
\text { octahydro-.alpha.,.alpha.,4a,8-tetramethyl-, } \\
\text { (2.alpha.,4a.beta. }\end{array}$ & Antimicrobial, ulcers and gastritis \\
\hline
\end{tabular}

Previous studies [15-33] on the composition of the oil from leaves of other Callistemon species showed that 1,8cineole is the main component in those species between (45-80\%), while 3 -pinene represents the major constituent in case of C. polandii, methyl eugenol in case of $C$. viridiflorous. [34-37] other authors observed that 1,8cineole $(53.03 \%)$ is the main component in Cc followed by eugenol $(12.1 \%)$, methyl eugenol $(8.3 \%)$, $\alpha$-terpineol (4.3\%) then carveol $(3.4 \%)$ in Callistemon. It was interesting to know that $\mathrm{Cc}$ produces high amount of cineole, eugenol and methyl-eugenol that those compounds are potent naturally occurring antimicrobial agent against broad spectrum of microorganisms and antifungal activity and it has also nematocidal activity and have good antioxidant activities. This directed the study to think about the influence of the volatile oil on the growth of certain microorganisms and as antioxidant.

[38] Manikandan et al., 2019 reported that, the GC-MS analysis has showed the different chemical constituents in the methanolic tuber extract of Momordica cymbalaria. A total of 23 chemical constituents were identified in the methanolic tuber extract of M. cymbalaria. At (16.98) retention time 2,4,6-Cycloheptatrien-1-one, 3,5-bis-trimeth,
Tetrasiloxane, decamethyl, and Methyltris (trimethylsiloxy) silane compound was found to be high $(11.17 \%)$ and the lowest percentage (1.88\%) was found to be Trimethyl (4tert-butylphenoxy) silane, Silicic acid, diethyl bis (trimethylsilyl) ester and Cyclotrisiloxane, hexamethyl. It can be used for the treatment of various diseases.

[39] Ramasubbu et al., 2020 reported that, there was 30 chemical components was identified from G.imberti and 13 components reported from $G$. travancorica. Hexahydrofarnesyl acetone was the dominant chemical component of the essential oil of G.imberti followed by Glycodeoxycholic acid, Ambrosin, Hexadecanoic acid and methyl ester. The essential oil of $G$. travancorica conquered by fatty acids and fatty acid derived compounds such as Geranyl acetone, Farnesyl acetone, Hexahydrofarnesyl acetone and the remaining bioactive compounds were dominated by oxygen-containing di, tri and sesquiterpenoids. The results of antimicrobial effect of essential oils of both species showed strong inhibitory activity even at lowest concentration $(10 \mu \mathrm{l})$ against 10 human pathogens. These results indicated that, the essential oil of both species is effective and might be applicable in nature medicines and novel drugs. 
The current study concludes that the highly active phytoconstituents of Eucalyptol; Octadien-3-ol, 3,7-dimethyl-; 1,5-Dimethyl-1-vinyl-4-hexenyl butyrate; L-.alpha.Terpineol and .alpha.-Terpineolpresent in the essential oil from leaves of Melaleuca citrina. It may be served as potent natural anti-cancer and anti-microbial compounds with important roles in human health and these compounds might be applicable in nature medicines.

\section{REFERENCES}

[1] Packiyalakshmi, D., Athilakshmi, P., Gayathri, S., Karthiga, P., Thiri Bhuvaneswari, R. and Manikandan, G. Antimicrobial potential of different solvents leaf extract of Millettia peguensis against selected pathogens. The Pharma Innovation Journal. 6(10): 119-124, 2017.

[2] Leelavathi M, Anitha L, Maheswarlu M, and Prasad NN. Standardization of the technology for the development of a Solanum torvum- Herbal based therapeutic lehyam. Asian Journal of Experimental Biological Sciences. 1: 758- 764, 2010.

[3] Manikandan, G., Vimala Rani, A., Divya, C. and Ramasubbu, R. GC-MS analysis of phytochemical constituents in the petroleum ether leaf extracts of Millettia peguensis. International Research Journal of Pharmacy. 8(9): 144-150, 2017.

[4] Hara-Kudo, Y., Kobayashi, A., Sugita-Konishi, Y. and Kondo, K. Antibacterial activity of plants used in cooking for aroma and taste. J. Food. Prot. 67: 2820-2824. 2004.

[5] Dragland, S., Senoo, H., Wake, K., Holte, K. and Blomhoff, R. Several culinary and medicinal herbs are important sources of dietary antioxidants. J. Nutr. 133: 1286-1290. 2003.

[6] Sakunphueak, A. and Panichayupakaranant, P. Comparison of antimicrobial activities of naphthoquinones from Impatiens balsamina. Nat. Prod. Res. 26: 1119-1124. 2012.

[7] Yang, X., Summerhurst, D.K., Koval, S.F., Ficker, C., Smith, F.L. and Bernards, M.A. Isolation of antimicrobial compound from Impatiens balsamina L. using bioassayguided fractionation. Phytother. Res. 15: 671-678. 2001.

[8] Dharmesh Kumar, Mahesh Sukapaka, G. D. Kiran Babu and Yogendra Padwad. Chemical Composition and in Vitro Cytotoxicity of Essential Oils from Leaves and Flowers of Callistemon citrinus from Western Himalayas. 10(8): e0133823. 2015

[9] Imad EddineHaoui, RatibaDerriche, LeilaMadani, ZahiaOukali. Analysis of the chemical composition of essential oil from Algerian Inula viscosa (L.) Aiton. Arabian Journal of Chemistry. 8(4): 587-590, 2015.

[10] Manohar, S.H., Poornananda, M.N., Patil, L.M. and Niranjana murthyhosakatte. Chemical composition of Garcinia Xanthochymus seeds, seed oil and evalution of its antimicrobial and antioxidant activity. J. of herbs, spices and medicinal plants. 20(2): 519 - 524. 2014

[11] Weyers W \& Brodbeck R. Skin absorption of volatile oils.
Pharmacokinetics Pharmazie in unserer Zeit, 18: 82-86. 1989.

[12] Laude EA, Morice AH \& Grattan TJ. The antitussive effects of menthol, camphor and cineole in conscious guinea-pigs. Pulmonary Pharmacology, 7: 179-184. 1994.

[13] Uemura M, Hata G, Toda T \& Weine FS. Effectiveness of EUC and d-limonene as gutta-percha solvents. Journal of Endodontics, 23: 739-741. 1997.

[14] Dogan H, Tasman F \& Cehreli ZC. Effect of gutta-percha solvents at different temperatures on the calcium, phosphorus and magnesium levels of human root dentin. Journal of Oral Rehabilitation, 28: 792-796. 2001.

[15] Silva CJ, Barbosa LCA, Demuner AJ, Montanari RM, Pinheiro AL, Andrade NJ. Chemical composition and antibacterial activities from the essential oils of Myrtaceae species planted in Brazil. Quim Nova. 33:104-8. 2010.

[16] Chane-Ming, J.; Vera, R.R.; Fraissed, J. Chemical composition of essential oil of Callistemon citrinus (Curtis) Skeel from Reunion. J. Esent. oil Res. 10, 429- 31. 1998

[17] Adonizio A L, Downum K, Bennett BC, Mathee K. Antiquorum sensing activity of medicinal plants in southern Florida. J Ethnopharmacol. 105:427-35. 2006.

[18] Mahmoud, I.I.; Marzouk, M.S.A.; Moharram, J.; Nolte, J.; Fobbe, R.; Saleh, M.I. Chemical composition of the Egyptian Callistemon lanceolatus DC. and Callistemon viminalis (Gaertner loudan) oils. Bull. Fac. Pharm. 40:11219. 2000.

[19] Paul I. Forster, Robert J., Goldsack A, Joseph J. Brophy. Leaf Essential Oils of the Australian Members of the Genus Callistemon (Myrtaceae). Journal of Essential Oil Research. 22:204-9, 1998.

[20] Oyedeji O.O., Oyedeji A. O., Shode F. O. and Lawal O. A. Volatile Constituents of the Leaf Oils of Callistemon salignus from Two Provinces in South Africa. Journal of essential oil research. 11:613-15. 2011.

[21] Michael M. Smyth and Erich V. Lassak. Steam Volatile Leaf Oil of Callistemon linearis (Schrader et Wendl.) Sweet. Journal of essential oil research. 6:403-6. 1994.

[22] Pierre MD Jazet1, Léopold N Tatsadjieu, Bernadin D Ndongson, Jean Kuate, Paul H Amvam Zollo1 and Chantal Menut. Correlation between chemical composition and antifungal properties of essential oils of Callistemon rigidus and Callistemon citrinus of Cameroon against Phaeoramularia angolensis. Journal of Medicinal Plants Research. 3:9-15. 2009.

[23] Kyoko Kobayachi, Tamaki Ishihara, Eriko khono, Toshio myasi and Fumihiko Yoshizaki. Constituents of Stem Bark of Callistemon rigidus Showing Inhibitory Effects on Mouse a-Amylase Activity. Biol. Pharm. Bull. 29:1275-77, 2006.

[24] Sherweit A.El-Ahmady, Nahla A.Ayoub, Abdel Nasser B.Singab, Mohamed M.Al-Azizi, Karl-Heinz Kubeczka. Chemical Composition and Antimicrobial Activity of the Essential Oils from Eucalyptus Cinerea, Callistemon Viminalis and Calothamnus Quadrifidus (Myrtaceae). Trade Science Inc. 3:28-34. 2007.

[25] Lounasmaa, M.; Puri, H.S.; Widen, C. Phloroglucinol 
derivatives of Callistemon lanceolatus leaves. Phytochemistry, 16:1851-52. 1977.

[26] Kobayashi, K.; Ishihara, T.; Khono, E.; Miyase, T.; Yoshizaki, F. Constituents of stem back of Callistemon rigidus showing inhibitory effects on mouse a-amylase activity. Biol. Pharmaceut. Bull. 29:1275-77. 2006.

[27] Saxena, S.; Gomber, C. Antimicrobial potential of Callistemon rigidus. Pharm. Biol. 3:194-201. 2006.

[28] Sunil Kumara, Vipin Kumara \& Om Prakasha. Antidiabetic, Hypolipidemic, and Antioxidant Activities of Callistemon lanceolatus Leaves Extract. Journal of Herbs, Spices \& Medicinal Plants 17:144-53. 2011.

[29] Brophy, J.J.; Lassak, E.V.; Toia, R.F. The volatile leaf oils of two cultivars of Callistemon viminalis. J. Proc. R. Soc. NSW. 118:101-4, 1986.

[30] Mohamed I. S. Abdelhady. Study of free fatty acids, hydrocarbons, sterols, triterpenes and essential oil contents and the antimicrobial activity of the egyptian Callistemeon viridiflorous (sims) sweet and Callistemon rigidus R. BR. J. Union Arab Biol. Cairo 47:139-46, 2009.

[31] Lorian V. "Antibiotics in Laboratory Medicine" 3rd ed., Williams and Wilkins, Hong Kong, London; 134-44p. 1988.

[32] Brophy, J.J.; Forster, P.I.; Goldsack, R.J.; Hibbert, D.B.; Punruckvong, A. Variation in 28. Callistemon viminalis (Myrtaceae): New Evidence from Leaf Essential Oils. Austral Syst. Bot. 10:1-13. 1997.

[33] Khan M., Srivastava S. K., Syamsundar K. V. and Anju K. Yadav. Chemical composition of Callistemon polandii leaf and stem essential oils from the plains of Northern India. Chemistry of Natural Compounds. 44:807-9, 2008.

[34] Kwon Park, Junheon Kim, Sang-Gil Lee, Sang-Chul Shin. Nematicidal Activity of Plant Essential Oils and Components from Ajowan (Trachyspermum ammi), Allspice (Pimenta dioica) and Litsea (Litsea cubeba) Essential Oils Against Pine Wood Nematode (Bursaphelenchus Xylophilus) Journal of Nematology. 39:275-79. 2007.

[35] Carson, C.F.; Riley, T.V. Antimicrobial activity of the major components of the essential oil of Melaleuca alternifolia. J. App. Bacteriol. 74:264-69. 1995.

[36] Dilip Kumar Das. Effects of arsenic contaminated irrigation water, zinc and organic matter on the mobilization of arsenic in soils in relation to rice (Oryza sativa L.), Arsenic n Soil and Groundwater Environment (Trace metals and other Contaminants in the Environment.), First Edition, 684, Elsevier B.V, 9:339-62, 2007.

[37] Dutta, B. K.; Karmakar, S.; Naglot, A.; Aich, J. C.; Begam, M. Anticandidial activity of some essential oils of a mega biodiversity hotspot in India. Mycoses, 50:121-24. 2007.

[38] Manikandan, G.; Pandiselvi, P.; Sobana, N.; Murugan, M. GC-MS analysis of chemical constituents in the methanolic tuber extract of Momordica cymbalaria Hook. F. Int. Res. J. Pharm. 10(1):135-140. 2019.

[39] Ramasubbu Raju; Manikandan Gurusamy; Sasi Kala Nambi. Phytochemical composition and antimicrobial properties of leaf essential oil of Garcinia imberti Bourd. and G. travancorica Bedd. International Journal of Advanced
Science and Technology, 29(2):1082-1092. 2020. 